\title{
Critical Success Factors of Hospital Management Information System (HMIS) Implementation in Developing Countries
}

\author{
Dionisius Alvian Ariwibowo, Dumilah Ayuningtyas
}

\begin{abstract}
Hospital Management Information System (HMIS) was a proficient tool to improve the quality of care by increasing the services effectiveness and efficiency in hospital. Unfortunately, the utilization of HMIS in developing countries was yet to be maximized when compared to that in developed countries. This study aimed to identify the critical success factor in implementing HMIS through SWOT (Strength, Weakness, Opportunity, and Threat) analysis. SWOT analysis is a powerful approach for evaluating the strengths and weaknesses of an entity from internal perspective, as well as the opportunities and threats from external perspective. The analysis showed that HMIS have the ability to provide more accurate data, timely available, faster documentation retrieval compared to paper-based system, and those considered as the HMIS implementation strengths. Competition in the hospital industry and government policies open the opportunity for immediate implementation of HMIS. Despite the benefits from implementing HMIS, the transition from the old to the new system has been rather slow. The hospital readiness from extra funding need, lack of skilled personnel, inadequate infrastructure to support system were a form of HMIS implementation weaknesses. External factors such as existing culture, technologies providers which underestimated healthcare complexity, also lack of communication and collaboration across organization became an obstacle that threatens HMIS implementation.
\end{abstract}

Index Terms: Critical Success Factors, Developing Countries, Hospital Management Information System, SWOT Analysis

\section{INTRODUCTION}

The rapid development of information technology system in health services environment, can be seen by looking at various innovation that involved information technology system inside [1]. Hospitals as health providers need to improve the quality of care in order to deliver better services to patients [2]. The involvement of information technology system to increase the quality of care, can be achieved with the use of Hospital Management Information System [3]-[4].

Hospital Management Information System (HMIS) was an information technology system which can support the health services in hospital to provide more effective and efficient services [3]. Globally, HMIS implemented to increase the quality of services by providing good-quality data, which can be used as reliable information source for decision making [1]

Revised Manuscript Received on July 20, 2019.

Dionisius Alvian Ariwibowo, Department of Health Policy and Administration, Faculty of Public Health Universitas Indonesia, Jakarta, Indonesia.

Dumilah Ayuningtyas (Corresponding Author), Department of Health Policy and Administration, Faculty of Public Health Universitas Indonesia, Jakarta, Indonesia.
Between developed and developing countries, there were differences in the HMIS implementation [3]-[5]. The progress of HMIS implementation in developed countries runs more smoothly compared to that in developing countries. This phenomenon generally caused by the differences of hospitals readiness in developing countries to adopt Information Technology in their services [3]-[4]-[5]. Despite the lack of readiness in execute HMIS in developing countries, there were some factors which encourage hospitals to immediately implement HMIS. Competition inside hospitals industry became one of the driving factors which stimulate every hospital to give the best services for the patients, and that can be achieved with HMIS support [3]. Some developing countries have policies issued by the government to appeal every hospital to implement HMIS [1]-[3]-[4]-[6].

Deep understanding of HMIS was necessary to understand the significance of implementing HMIS and advantages and disadvantages that came with it. Strength, Weakness, Opportunity, and Threat (SWOT) analysis can be a powerful approach to identify the Critical Success Factors (CSF's) in HMIS implementation. SWOT analysis usually used to evaluate and identify an organization from each element. However, SWOT analysis can also be used to evaluate information technology system [7]-[8].

This study aimed to identify Critical Success Factors (CSF's) on HMIS implementation in developing countries. SWOT analysis was used as a tool to identify each CSF. Developing counties that used in this study were Indonesia, Malaysia, Thailand, India, and Kenya [7]-[8].

\section{METHODOLOGY}

Strength, Weakness, Opportunity, and Threat (SWOT) Analysis was used to determine the internal and external factor in the implementation of Hospital Management Information System (HMIS). Internal factors consist of strengths and weaknesses, while external factors consist of opportunities and threat. Data were collected by carrying out literature review from ProQuest, IOP Science, EBSCOhost, Emerald Insight and Science Direct within year 2010-2019. Evidence which showed the advantages of HMIS implementation within internal setting will be categorized as strength, while the disadvantages within internal setting will be categorized as weakness.

\section{Published By:}


Evidence which showed the advantages of HMIS implementation within external setting will be categorized as opportunities and the disadvantages will be categorized as threat.

Evidences that consistently appeared in most of the literature will be used as components which can determine the Critical Success Factors (CSF's) in the implementation of HIMS. CSF's were categorized by dividing them into internal perspective from strength and weakness analysis, and external perspective from opportunities and threat analysis.

\section{RESULT}

\section{A. SWOT Analysis}

Various aspects affected the implementation of Hospital Management Information System (HMIS). Starting from internal aspect, such as the user proficiency, technology quality, infrastructure, system integration, etc. Until external aspects such as government involvement, HMIS provider, healthcare services culture, user training, etc. The following is a list of the results for each SWOT analysis elements regarding to HMIS implementation:

\section{1) Strengths of HMIS Implementation in developing} countries

Most of the studies showed HMIS can improve the effectiveness and efficiency of services. Technically by providing better data, timely available, human error reduction, and can cut user work time compared to paper-based system [1]-[3]-[5]-[9]. The ability of HMIS to provide faster documentation retrieval and high data accuracy enable hospital officer to reduce patients waiting times, manage resources better, and enhanced accountability in hospital [3].

Research in Kenya showed HMIS that was implemented in that country was user-friendly [3]. User-friendly system was necessary so that user will learn new system easier [10]. Less user-friendly system would lead to hospital workers resistance in learning and implementing new HMIS [9]. In Thailand, the internet connection was considered as speedier than other developing countries which enable HMIS to operate better [6].

Medical error and adverse drug reaction caused by illegible prescription when using conventional prescription could also be reduced [5]. In Malaysia, Physician and other medical personnel confirmed that much more information they can get in one place compared to conventional paper-based method [10]. In India HMIS provide system-generated appointment reminders which can improve patient follow-up [5].

\section{2) Weaknesses of HMIS implementation in developing countries}

Compared to developed countries there were still many obstacles preventing successful HMIS implementation [3]-[9]. In Kenya, despite of the benefit when using HMIS, health data provided by HMIS was barely used by hospital officer for service delivery and decision making [3]. Almost all workers from all countries used in this study have lacking computer skills, which affect their work [5]. Some HMIS in Indonesia was not integrated from one system to another or even to other non-information technology system, so workers sometimes need to handle both paper and electronic documentation [9]-[11].
Complete HMIS integration was still a challenge in perfecting HMIS. Some hospital departments have yet to adopt information system in their services. If all departments were not completely using HMIS, the system will be ineffective because data became scattered in electronic format and conventional paper-based format [9].

In Indonesia, few resource and investment were given to HMIS development [1]-[9]. Inadequate resources allocation to succeed HMIS implementation can be seen from few information and communication technology staff to assist trouble, not sufficiently equipped Information Technology (IT) infrastructure, and low HMIS maintenance [1]-[3]-[5]-[6]-[9]. Poor maintenance which resulted in poor connection or system error lead to strains between front office worker and patients during peak operation hours [5]. Dissatisfied patients can become reflection of low-quality services [4].

Most government had standard information which must be loaded inside HMIS. Research from Kenya showed only about half of the HMIS software were able to fulfill the information as contained in government policies [12]. Slow development of HMIS in developing countries can inhibit changeover between the new and old system [9].

\section{3) Opportunities of HMIS implementation in developing countries}

Changing to HMIS from conventional paper-based system was assessed as necessary. Developing countries were realized the need to embrace information and communication technologies to deal with healthcare problems such as access, quality, and cost [3]-[13]. Healthcare delivery will greatly be affected, if accurate records were not maintained properly, or patients got different care when they got services from other departments [3]. In Kenya, those views already considered by healthcare providers, which can open the opportunity for HMIS to join the industry [3]-[4].

Globally there was escalation in competitiveness and advancement of hospital industry technology [10]. Hospital in developing countries demanded to follow the industry trend to provide quality patients care [3]-[10]. Maximal utilization of data that had been recorded by HMIS can bring benefits for healthcare needs in bigger scale. The data can be aggregated on national or global level for decision-making process [12].

Indonesia government issued policies related to HMIS. The Act of Republic Indonesia No 44/2009 article 52 verse (1) stated that every hospital is obliged to conduct the recording and reporting of its activities and process. Recording and reporting which are stated in the policy above supported by Regulation of Ministry of Health No. 82/2013 about Hospital Management Information System, which appealed every hospital in Indonesia to implement HMIS to support the service process, including recording and reporting [14]. Similar policies were also applied in various other developing countries [4]-[12].

Policies would greatly affect public government-owned hospitals into changing their system, because they have obligation to comply with policies issued by government [4]. 
Overall the competition, technology advancement, and policies can become great opportunities to make hospitals starts implementing HMIS into their services [3]-[4]-[10]-[12]-[14].

\section{4) Threats of HMIS implementation in developing countries}

In the most developing countries, use of computer in care delivery has not been a widespread practice. Adequate training is a necessary need to improve hospital workers skill [3]. In Indonesia, some research showed there was a lack of training for users to be completely proficient in operating HMIS [9]-[11]. Lack of training can threaten HMIS implementation from user aspect. The difficulties to operate HMIS by the users can stressed them and eventually lead to the possibility of resistance to use HMIS [12].

HMIS can be developed by the hospital itself or by third parties. Sometimes technology companies which developed HMIS underestimate the complexity of health domain, with assumption that if they manage to develop technology in another sector, then they will also succeed in health sector [3]. Another research showed that providers met some obstacles such as small number of successful programs, financial cost, and lack of technology advocates which slowed their progress [10].

Insufficient communication and collaboration across organization related to HMIS in developing countries inhibit the development of HMIS [6]. Most research showed there was a culture in healthcare setting, where workers were not used to using information and communication technology in their service process. Lack of senior management support is often stated as the number one cause of information and communication technology program failures [3].

Evidence from Indonesia and India showed that written guidelines, supervision, and feedback from upper management were considered as lacking even they greatly affects compliance of HMIS [5]-[13]. Good guidelines, supervision, and feedback can cope with workers lack of knowledge, especially about what should be documented and how to do the right documentation. Overall, all threats that have been explained above, if not handled well would lead to hospital officer resistance in using HMIS [11].

\section{B. Critical Success Factors (CSF's) for HMIS implementation}

Critical success factors (CSF's) were formulated based on SWOT analysis above. Table I below showed each CSF's in HMIS implementation, from strength, weakness, opportunity, and threat elements. CSF's from strength and opportunities are considered positive (+) factors which will succeed HMIS if implemented. On the contrary, CSF's from weakness and threat are considered negative (-) factors which will made HMIS implementation failed if not handled.

Table-I CSF's in HMIS Implementation

\begin{tabular}{|c|c|c|c|c|c|}
\hline \multirow[t]{2}{*}{ Elements } & \multicolumn{5}{|c|}{ Critical Success Factor's } \\
\hline & Indonesia & Malaysia & Thailand & India & Kenya \\
\hline Strengths (+) & $\begin{array}{l}\text { - Current HMIS was } \\
\text { able to provide } \\
\text { accurate data, } \\
\text { timely available, } \\
\text { and easier retrieval } \\
\text { compared to old } \\
\text { paper-based } \\
\text { system } \\
\text { - New prescription } \\
\text { using information } \\
\text { technology system } \\
\text { reduce the medical } \\
\text { error caused by } \\
\text { illegible } \\
\text { prescription }\end{array}$ & $\begin{array}{l}\text { - Current HMIS was } \\
\text { able to provide } \\
\text { accurate data, } \\
\text { timely available, } \\
\text { and easier retrieval } \\
\text { compared to old } \\
\text { paper-based } \\
\text { system } \\
\text { - Information can be } \\
\text { retrieved from one } \\
\text { place compared to } \\
\text { conventional } \\
\text { paper-based } \\
\text { method }\end{array}$ & $\begin{array}{l}\text { - Current HMIS was } \\
\text { able to provide } \\
\text { accurate data, } \\
\text { timely available, } \\
\text { and easier retrieval } \\
\text { compared to old } \\
\text { paper-based } \\
\text { system } \\
\text { - Stable connection } \\
\text { compared to } \\
\text { another developing } \\
\text { countries } \\
\text { - New prescription } \\
\text { using information } \\
\text { technology system } \\
\text { reduce the medical } \\
\text { error caused by } \\
\text { illegible } \\
\text { prescription }\end{array}$ & $\begin{array}{l}\text { - Current HMIS was } \\
\text { able to provide } \\
\text { accurate data, } \\
\text { timely available, } \\
\text { and easier retrieval } \\
\text { compared to old } \\
\text { paper-based } \\
\text { system } \\
\text { - New prescription } \\
\text { using information } \\
\text { technology system } \\
\text { reduce the medical } \\
\text { error caused by } \\
\text { illegible } \\
\text { prescription }\end{array}$ & $\begin{array}{l}\text { - Current HMIS was } \\
\text { able to provide } \\
\text { accurate data, } \\
\text { timely available, } \\
\text { and easier retrieval } \\
\text { compared to old } \\
\text { paper-based } \\
\text { system } \\
\text { - Providers were able } \\
\text { to develop } \\
\text { user-friendly } \\
\text { system }\end{array}$ \\
\hline Weaknesses (-) & $\begin{array}{l}\text { - Insufficient } \\
\text { funding and } \\
\text { investment } \\
\text { - Lack of } \\
\text { infrastructure } \\
\text { - Unintegrated } \\
\text { system } \\
\text { - Inadequate ICT } \\
\text { staff } \\
\text { - Unskilled } \\
\text { personnel who } \\
\text { operate HMIS } \\
\text { - Slow new and old } \\
\text { system transition }\end{array}$ & $\begin{array}{l}\text { - Lack of } \\
\text { infrastructure } \\
\text { - Inadequate ICT } \\
\text { staff } \\
\text { - Unskilled } \\
\text { personnel who } \\
\text { operate HMIS }\end{array}$ & $\begin{array}{l}\text { - Unskilled } \\
\text { personnel who } \\
\text { operate HMIS }\end{array}$ & $\begin{array}{l}\text { - Lack of } \\
\text { infrastructure } \\
\text { - Inadequate ICT } \\
\text { staff } \\
\text { - Unskilled } \\
\text { personnel who } \\
\text { operate HMIS }\end{array}$ & \begin{tabular}{|l} 
- Health data \\
generated by \\
HMIS barely used \\
by \\
decision-makers \\
- Lack of \\
infrastructure \\
- Unskilled \\
personnel who \\
operate HMIS \\
- Information \\
provided did not \\
follow current \\
standard
\end{tabular} \\
\hline
\end{tabular}




\begin{tabular}{|c|c|c|c|c|c|}
\hline $\begin{array}{l}\text { Opportunities } \\
(+)\end{array}$ & $\begin{array}{l}\text { - Government } \\
\text { already issued } \\
\text { policies and } \\
\text { guidelines to } \\
\text { promote HMIS } \\
\text { implementation } \\
\text { - Global competition } \\
\text { in hospitals } \\
\text { industry } \\
\text { - Data generated by } \\
\text { HMIS can be } \\
\text { aggregated on } \\
\text { national }\end{array}$ & $\begin{array}{l}\text { - Government } \\
\text { already issued } \\
\text { policies and } \\
\text { guidelines to } \\
\text { promote HMIS } \\
\text { implementation } \\
\text { - Global competition } \\
\text { in hospitals } \\
\text { industry }\end{array}$ & $\begin{array}{l}\text { - Government } \\
\text { already issued } \\
\text { policies and } \\
\text { guidelines to } \\
\text { promote HMIS } \\
\text { implementation } \\
\text { - Global competition } \\
\text { in hospitals } \\
\text { industry }\end{array}$ & $\begin{array}{l}\text { - Government } \\
\text { already issued } \\
\text { policies and } \\
\text { guidelines to } \\
\text { promote HMIS } \\
\text { implementation } \\
\text { - Global competition } \\
\text { in hospitals } \\
\text { industry }\end{array}$ & $\begin{array}{l}\text { - Healthcare } \\
\text { providers already } \\
\text { considered the } \\
\text { importance of } \\
\text { information } \\
\text { technology } \\
\text { implementation in } \\
\text { health sectors } \\
\text { - Government } \\
\text { already issued } \\
\text { policies and } \\
\text { guidelines to } \\
\text { promote HMIS } \\
\text { implementation } \\
\text { - Global competition } \\
\text { in hospitals } \\
\text { industry }\end{array}$ \\
\hline Threats (-) & $\begin{array}{l}\text { - The use of } \\
\text { computer in } \\
\text { healthcare setting } \\
\text { was not a } \\
\text { widespread } \\
\text { practice } \\
\text { - Lack of training to } \\
\text { increase personnel } \\
\text { proficiency in } \\
\text { operating HMIS } \\
\text { - Weak } \\
\text { communication } \\
\text { and collaboration } \\
\text { related to HMIS } \\
\text { - Lack of written } \\
\text { guidelines, } \\
\text { supervision, and } \\
\text { feedback from } \\
\text { upper management }\end{array}$ & $\begin{array}{l}\text { - The use of } \\
\text { computer in } \\
\text { healthcare setting } \\
\text { was not a } \\
\text { widespread } \\
\text { practice } \\
\text { - Weak } \\
\text { communication } \\
\text { and collaboration } \\
\text { related to HMIS }\end{array}$ & $\begin{array}{l}\text { - The use of } \\
\text { computer in } \\
\text { healthcare setting } \\
\text { was not a } \\
\text { widespread } \\
\text { practice } \\
\text { - Weak } \\
\text { communication } \\
\text { and collaboration } \\
\text { related to HMIS }\end{array}$ & $\begin{array}{l}\text { - The use of } \\
\text { computer in } \\
\text { healthcare setting } \\
\text { was not a } \\
\text { widespread } \\
\text { practice } \\
\text { - Weak } \\
\text { communication } \\
\text { and collaboration } \\
\text { related to HMIS }\end{array}$ & $\begin{array}{l}\text { - The use of } \\
\text { computer in } \\
\text { healthcare setting } \\
\text { was not a } \\
\text { widespread } \\
\text { practice } \\
\text { - Technology } \\
\text { companies which } \\
\text { provide HMIS } \\
\text { often } \\
\text { underestimate } \\
\text { healthcare services } \\
\text { complexity } \\
\text { - Weak } \\
\text { communication } \\
\text { and collaboration } \\
\text { related to HMIS } \\
\text { - Lack of written } \\
\text { guidelines, } \\
\text { supervision, and } \\
\text { feedback from } \\
\text { upper management }\end{array}$ \\
\hline
\end{tabular}

Every developing country above already has HMIS which had the abilities to provide accurate data, timely available, and easier retrieval compared to old paper-based system. HMIS in Indonesia, Thailand, and India also have new prescription system which can become solution of illegible prescription. Malaysia had HMIS which can be retrieved information from one place, and Kenya had HMIS that user-friendly. Thailand has stable internet connection to support HMIS operation. Each of evidence mentioned before were positive CSF's from strengths element which can be adopted and strengthened in order to succeeding HMIS implementation in developing countries.

Lack of infrastructure to support HMIS and unskilled personnel who operate HMIS are considered the weaknesses of HMIS implementation in almost all developing countries. Studies from Indonesia, Malaysia, and India showed Information Communication Technology (ICT) staffs were lacking in giving assistance when necessary. Insufficient funding and investment in HMIS development, unintegrated system, and slow old and new system transition were weaknesses found in Indonesia. Health data generated by HMIS barely used by decision makers and poor connection quality were weaknesses found in Kenya. The weaknesses of HMIS implementation in those countries were negative CSF's and need to be handled in order to avoid failure in HMIS implementation.

Government from all countries in this study already issued policies and guidelines to promote HMIS in healthcare industry. Global competition in healthcare industry push hospitals in all countries to immediately adopt information and communication technology in their services. Study in Indonesia showed data generated by HMIS can be aggregated on national level. Healthcare providers in Kenya already put attention to IT importance in their services. Those statement were positive CSF's from opportunities perspective which will support the HMIS implementation. The use of computer in healthcare setting was not a widespread practice in most developing countries. Weak communication and collaboration across organization regarded to HMIS became major threat which inhibit the implementation of HMIS. There were lack of guidelines, supervision, and feedback from upper management in studies from Indonesia and Kenya. Lack of personnel training persists in Indonesia. In Kenya, technology companies which provide HMIS often underestimate healthcare services complexity. Situation as mentioned before were negative CSF's from threat element and it was important to confront it in order to avoid failure in HMIS implementation. 


\section{DISCUSSION}

Overall Hospital Management Information System (HMIS) can give many benefits for business process in hospitals which can improve healthcare services provided by hospitals [1]-[3]-[9]-[15]. Although some studies showed HMIS still imperfect, but it still superior compared to the old paper-based system. While considered as superior, the transition of the new and old system is still facing many difficulties. Many factors contribute to the transition difficulties, from the system imperfectness until the culture in healthcare setting itself that still not used to technology practices in services delivery, for example in hospital's logistics [9]-[10]-[16].

Competition in healthcare industries including hospitals became one of the driving factors that makes hospital should consider immediate adoption and perfecting their management information system. HMIS implementation became a need in order to increase their competitiveness in the industry. This situation was an opportunity for HMIS itself to be implemented immediately in all hospitals [3]-[4]-[10]-[12]-[14].

The benefits of HMIS not only can be obtained by hospital but also by health sector across national level or even global level. The data recorded by HMIS was easier to be disseminated compared to the data recorded by paper. Stakeholders and any other decision maker can use the data to improve and develop healthcare as whole [3].

To achieve perfect HMIS, management need to invest more resources and funds on information and communication technology (ICT) department. In developing countries, ICT investment is considered less popular compared to another sectors. Extra investment in technology can give benefits in long-term adoption [1]-[9].

A certain level of proficiency is necessary to operate HMIS. Training is one of the solutions to teach new skills to users. Unfortunately, the trainings for users to master HMIS were still lacking in the most study. Untrained users will face difficulty in operating HMIS and can result in user resistance to using HMIS [3]-[9].

Government have a big part in the HMIS implementation. Policies and guidelines issued by government will help HMIS implemented in the healthcare services. Policies which issued by government have power to make hospitals, especially government-owned public hospital to comply with those policies. Various developing countries already issued policies and guidelines to promote the importance to implement HMIS in the healthcare delivery [4]-[12]-[14].

\section{CONCLUSION}

Information technology implementation in hospital unavoidably will be beneficial for many parties. In order to succeed it, communication and collaboration from various sectors were necessary so that HMIS can be developed perfectly. Further studies are required to explore HMIS implementation more deeply. Overall, despite the boundaries holding back HMIS implementation, the healthcare industries trend showed the needs for hospitals to implement information technology in their services.

\section{REFERENCES}

1. H. Ahmadi, M. Nilashi, L. Shahmoradi, O. Ibrahim, "Hospital Information System adoption: Expert perspectives on an adoption framework for Malaysian public hospitals," in Computer Human Behavior 67. 2017, pp. 161-189.

2. F. Greaves, A.A Laverty, D. Ramirez. "Tweets about hospital quality: A mixed methods study," in BMJ Qual Saf. 2014, pp. 838-846.

3. M. G. Nkanata, E.O. Makori, G. Irura, et al, "Comparative Analysis of Hospital Information Management Systems Among Healthcare Workers in Two Selected Hospitals in Kenya," in Library Philosophy and Practice (e-journal), 2018.

4. E. Kihuba, D. Gathara, S. Mwinga, et al, "Assessing the ability of health information systems in hospitals to support evidence-informed decisions in Kenya. Glob Health Action,” 2014, pp. 1-10.

5. K. Mukherjee, P.A. Babu, "Economic evaluation of hospital management information systems in Tamil Nadu, India," in Int J Med Public Heal, 2014.

6. K. Narattharaksa, M. Speece, C. Newton, D. Bulyalert, "Key success factors behind electronic medical record adoption in Thailand," in $J$ Heal Organ Manag, 2016, pp. 985-1008.

7. G. Büyüközkan, Ö, Ilıcak," Integrated SWOT analysis with multiple preference relations," in Kybernetes. 2018, pp.451-470.

8. P. Trkman, "The critical success factors of business process management," in Int J Inf Manage, 2010, pp. 125-134.

9. P. Y. Lenny, S. Kridanto, "Analysis of user acceptance, service quality, and customer satisfaction of hospital management information system," in Journal of Physics: Conference Series 1193, 2019.

10. N. Zakaria, S. A. Mohd Yusof, "Understanding Technology and People Issues in Hospital Information System (HIS) Adoption: Case study of a tertiary hospital in Malaysia," in J Infect Public Health, 2016, pp. 774-780.

11. R. T. S Hariyati, N. Kobayashi, J. Sahar,"Simplicity and Completeness of Nursing Process Satisfaction Using Nursing Management Information System at the Public Health Service "X" Indonesia," in International J caring Sci, 2018, pp.1034-1042.

12. T. Suganthalakshmi, M. Priya, S. Thirunavukkarasu," A Study on Health Management Information System (HMIS) with reference to Periyanaickenpalayam Government Hospital, Coimbatore," in $J$ Contemp Res Manag. 2016;11(2):1-17.

13. W. Shalannanda, R. Hakimi," IT Governance design for Hospital Management Information System case study: X hospital," in Proceeding 2016 10th Int Conf Telecommunication Syst Serv Appl TSSA, 2016.

14. A. Sankarganesh, T. Senthilkumar, N. Venketesh, P. Soundararajan," The role of chest physiotherapy on pulmonary outcome in patients with renal dysfunction," in Indian J Public Heal Res Dev, 2018, pp. 1-5.

15. H. T. Andreica, I. Doros," Bussiness Reporting using Web Technology," in Metal Int vol XVI no 7 63, 2011.

16. D.C Feibert, P. Jacobsen," Factors Impacting Technology Adoption in Hospital Bed Logistics," in international journal of logistic management Vol 30, 2019, pp. 195-230

\section{AUTHORS PROFILE}

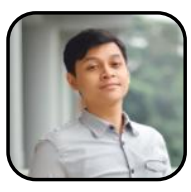

Dionisius Alvian Ariwibowo, currently an undergraduate student in Department of Policy and Administration Faculty of Public Health Universitas Indonesia. The internship experience from Public Hospital in Jakarta, became his research starting point in hospital information management system. His prior research regarded to information technology system was about the implementation of Technology Acceptance Model in a hospital in Jakarta City.

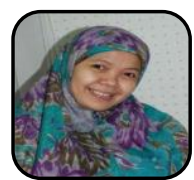

Dumilah Ayuningtyas, received her Master in Hospital Administration and Doctoral degree from Universitas Indonesia. Most of her research is associated with health policy and hospital management. She is currently a lecturer in Faculty of Public Health Universitas Indonesia. She is passionate about health system and policy, as well as strategic management, and already published a few books about health policy and also strategic planning in healthcare organization. 